\title{
Anteseden Kepercayaan dan Implikasinya terhadap Perilaku Tenaga Profesional pada Wakaf Tunai
}

\author{
Ahadin Sadri ${ }^{1, *}$ \\ ${ }^{1}$ Institut Ilmu Sosial dan Manajemen STIAMI, Jakarta, Indonesia \\ 1 ahadinsadri@bas.co.id* \\ * corresponding author
}

\section{ARTICLE INFO}

\section{Article historv}

Received 2019-11-04

Revised 2019-12-16

Accepted 2019-12-18

Keywords

Trust,

Intention,

Wakaf Tunai

\begin{abstract}
$A B S T R A C T$
The development of cash waqf in Indonesia is less encouraging, although cash waqf has entered into law since 15 years ago. Starting from this background, this research intends to investigate the public's desire, in this case professional groups, to make cash endowments. This research assumes that the desire to represent cash is due to the trustworthiness of nazhir. This study examines antecedents that cause public trust in cash waqf, so they wish to do cash waqf. The results of the study indicate that all hypotheses are proven to have a positive effect, except situational normality which has a negative effect on trust of services.
\end{abstract}

\section{PENDAHULUAN}

Undang-undang No. 41 Tahun 2004 tentang Wakaf telah memperluas cakupan wakaf. Wakaf tidak lagi hanya terbatas pada benda tidak bergerak (seperti tanah, bangunan), namun benda bergerak pun dapat diwakafkan. Wakaf benda bergerak tersebut disebut wakaf uang atau wakaf tunai. Pengertian wakaf uang adalah penyerahan hak milik berupa uang dari orang yang mewakafkan (wakif) kepada seseorang/institusi penerima wakaf (nadzir) dengan ketentuan bahwa hasil atau manfaatnya digunakan untuk hal-hal yang sesuai dengan ajaran syariat Islam dengan tidak mengurangi ataupun menghilangkan jumlah pokoknya (Syauqi, 2017).

Setelah hampir 15 tahun sejak kelahiran UU No. 41/2004, atau 13 tahun setelah lahir Peraturan Pemerintah No. 42 Tahun 2006 tentang Pelaksanaan Undang-Undang Nomor 41 Tahun 2004 tentang Wakaf; perkembangan wakaf tunai belum menunjukkan hasil yang signifikan. Memang ada beberapa studi kasus yang menunjukkan keberhasilan wakaf tunai. Misalnya, penelitian Fahham (2015) menunjukkan keberhasilan wakaf tunai yang diselenggarakan sejak 2011 oleh Pengurus Wikayah Nahdlatul Ulama Yogyakarta yang berhasil memutarkan hasil wakaf tunai menjadi pinjaman tidak berbunga. Namun tidak sedikit pula kisah kekurangbethasilan pengelolalaan wakaf tunai. Bahkan ada sebagian kecil masyarakat muslim yang masih memperdebatkan kesahihan wakaf tunai ini (Atabik, 2014).

Padahal di negara-negara Islam lain atau negara yang penduduknya mayoritas Islam seperti Bangladesh, Yordania, dan Mesir, wakaf termasuk wakaf tunai telah berjalan relatif lebih baik. Sementara itu potensi wakaf tunai di negara-negara Islam sangat besar (Atan \& Johari, 2017), sebagaimana dibuktikan di beberapa sejumlah negara bagian di Malaysia (Haron, Kamarudin, Fauzi, dan Arif, 2016).

Penelitian ini hendak mengetahui faktor-faktor yang menyebabkan seseorang berkeinginan untuk melakukan wakaf tunai. Salah satu faktor yang menentukan keberhasilan penghimpunan wakaf tunai (cash waqaf) adalah kepercayaan (trustworthiness) wakif terhadap nadzir, seperti hasil penelitian Hasan \& Siraj (2017), Saiti (2917), Fauzi, Yahya, Hanaysha, Haron, dan Zahrin (2019), dan Hasan, Siraj, Mohammad (2019). Penelitian Ahmed, Mohammed, Faosiy, dan Daud (2016) di Uganda menyimpulkan bahwa dari 320 responden, mayoritas tidak mempercayai badan-badan keagamaan Islam di negara itu mengingat pemimpin mereka tidak bisa dipercaya, tidak akuntabel, tidak transparan, tidak dapat diandalkan, tidak kompeten, dan tidak jujur. 
Berdasarkan permasalahan empiris dan beberapa hasil penelitian terdahulu tersebut, maka penelitian ini hendak meneliti faktor-faktor yang mempengaruhi kepercayaan (trustworthiness) wakif terhadap nadzir,; dan menguji pengaruh kepercayaan wakif terhadap niat wakif untuk mewakafkan uang tunai mereka.

Berdasarkan latar belakang dan model penelitian, maka masalah penelitian ini adalah menguji pengaruh variabel antiseden bagi kepercayaan (customers' trust for services), dan pengaruh kepercayaan terhadap customer behavioral intention, yakni niat wakif untuk mewakafkan uang tunai. Permasalahan ini dirinci dalam pertanyaan penelitian sebagai berikut:

1. Apakah consumer's familiarity secara positif mempengaruhi customers' trust for services?

2. Apakah consumer's perception of structural assurance secara positif mempengaruhi customers' trust for services?

3. Apakah consumer's perception of situational normality secara positif mempengaruhi customers' trust for services?

4. Apakah consumer's perception of calculative-based trust secara positif mempengaruhi customers' trust for services?

5. Apakah consumer's disposition secara positif mempengaruhi customers' trust of services?

6. Apakah customers' trust for services secara positif mempengaruhi customer behavioral intention?

\section{KAJIAN PUSTAKA}

Selain mengenai wakaf dan wakaf tunai, kajian pustaka ini mengkaji variabel-variabel yang terdapat pada konstruk penelitian Wang, Ngamsiriudom, dan Hsich (2017). Konstruk tersebut terdiri atas tujuh variabel, yang terdiri dari lima variabel sebagai antiseden customers' trust of services (yakni consumer's familiarity, consumer's perception of structural assurance, consumer's perception of situational normality, consumer's perception of calculative-based trust, consumer's disposition), customers' trust of services, dan customer behavioral intention).

\section{Wakaf dan Wakaf Tunai}

Wakaf (Arab: waqofa) berarti menahan sesuatu, atau berhenti di tempat. KBBI.web.id memberikan tiga arti wakaf, salah satunya benda bergerak atau tidak bergerak yang disediakan untuk kepentingan umum (Islam) sebagai pemberian yang ikhlas. Undang-undang No. 41 Tahun 2004 tentang Wakaf mendefinisikan wakaf sebagai perbuatan hukum wakif (pihak yang mewakafkan harta benda miliknya, red.) untuk dimanfaatkan selamanya atau untuk jangka waktu tertentu sesuai dengan kepentingannya guna keperluan ibadah dan/atau kesejahteraan umum menurut syariah.

Nadzir, adalah pihak yang menerima harta benda wakaf dari wakif untuk dikelola dan dikembangkan sesuai dengan peruntukannya. Nadzir meliputi perseroangan, organisasi, atau badan hukum. Sesuai dengan Pasal 11 UU 41/2004, nadzir mempunyai tugas: (a) melakukan pengadminitrasian harta benda wakaf; (b) mengelola dan mengembangkan harta benda wakaf sesuai dengan tujuan, fungsi dan peruntukannya; (c) mengawasi dan melindungi harta benda wakaf; dan (d) melaporkan pelaksaaan tugas kepada Badan Wakaf Indonesia.

\section{Customer Behavioral Intention}

Model penelitian yang penulis anggap cocok dengan permasalahan ini adalah model penelitian yang digunakan oleh Wang, Ngamsiriuom, \& Hsieh (2015). Model tersebut diharapkan dapat menjawab sebagian permasalahan penting yang dihadapi oleh wakaf tunai di Indonesia.

\section{Consumer's Familiarity}

Terbiasa, keakraban, atau kenal baik dengan penyedia layanan (consumer's familiarity) merupakan antiseden kepercayaan. Familiarity ini memungkinkan konsumen untuk menempatkan kepercayaan mereka tentang masa depan ke dalam konteks yang mengklarifikasi apa, kapan, di mana, dan bagaimana terjadinya dampak yang diperoleh dari pihak lain (Wang et al., 2015).

Gefen (Wang et al., 2015) menyatakan bahwa keakraban dengan service provider berasal dari pengalaman dan pengetahuan berlandaskan interaksi sebelumnya, termasuk proses pembelian, proses 
bagaimana memperoleh pelayanan. Menurut Wang et al. (2015) kepercayaan berkembang dari waktu ke waktu dengan akumulasi pengetahuan yang relevan dengan kepercayaan yang dihasilkan dari pengalaman dengan pihak lain.

Terbiasa (familiarity) dengan cara mitra bisnis melakukan bisnis, dan keterbatasan mereka, juga merupakan antiseden pentimg dari kepercayaan dalam interaksi bisnis yang berkelanjutan (Kumar dalam Wang et al., 2015). Oleh karena itu semakin akrab dengan service providers, semakin konsumen mudah memilih/ menggunakan produk/ jasa mereka. Penelitian Wang et al. (2017) membuktikan terdapat hubungan positif dan signifikan antara disposition terhadap trust Berdasarkan kajian teoritis tersebut, maka diajukan hipotesis sebagai berikut:

Hipotesis 1: Terdapat pengaruh consumer's familiarity secara positif terhadap , consumer's disposition

\section{Consumer's Perception of Structural Assurance}

Pesepsi konsumen mengenai jaminan struktural (consumer's perception of structural assurance) adalah persepsi kepercayaan tentang lingkungan kelembagaan (McKnight, 2003b) yang merujuk pada jaring pengaman seperti sumber daya hukum, jaminan, dan regulasi dalam konteks yang spesifik. Dalam kontek $m$ cemmerce, jaminan struktural ini adalah persepsi mengenai ketersediaan struktur hukum dan teknis yang diperlukan seperti enkripsi (encryption), jaminan, asuransi, regulasi, atau prosedur lain pada bisnis/kegiatan jaringan nirkabel internet yang berfungsi sebagai penyangga (buffer) untuk memastikan penyelesaian transaksi keuangan yang berhasil antara konsumen dengan service provider.

Ketika konsumen menangkap isyarat hadirnya jaminan struktural, maka kepercayaan konsumen dalam bertransaksi akan meningkat.Penelitian Wang et al. (2017) membuktikan terdapat hubungan positif antara consumer's perception dan signifikan antara disposition terhadap trust. Berdasarkan hasil penelitian terdahulu tersebut, maka disusun hipotesis sebagai berikut:

Hipotesis 2: Terdapat pengaruh consumer's perception of structural assurance secara positif terhadap customers' trust of services

\section{Consumer's Perception of Situational Normality}

Persepsi konsumen mengenai normalitas situasional (consumer's perception of situational normality) merujuk pada persepsi konsumen mengenai seberapa normal atau bagaimana situasinya kelihatannya (Gefen, 2003). Kepercayaan konsumen akan menurun jika konsumen menilai bahwa situasi tidak normal. Oleh karena itu orang cenderung memberikan kepercayaan yang lebih besar ketika sifat interaksi sesuai dengan apa yang mereka anggap normal, yang berarti tidak ada harapan yang dilanggar.

Dalam konteks e-business, ketikan konsumen terlibat dengan situs e-business, konsumen membentuk harapan merteka berdasarkan pengalaman dan pengetahuan mereka tentang transkasi serupa lainnya. Apabila konsumen tidak menemukan sesuatu pelanggaran dari harapan mereka, atau dari prosedur atau situasi normal, maka konsumen akan memberikan kepercayaan kepada service provider tersebut (Wang et al., 2015). Berdasarkan hasil penelitian terdahulu tersebut, maka disusun hipotesis sebagai berikut:

Hipotesis 3: Terdapat pengaruh consumer's perception of situational normality secara positif terhadap customers' trust of service.

\section{Consumer's Perception of Calculative-Based Trust}

Persepsi konsumen mengenai kepercayaan berbasiskan kalkulasi consumer's perception of calculative-based trust) merujuk pada penilaian rasional atas biaya dan manfaat dalam berhubungan dengan service provider (Gefen, Straub, Boudreau, 2003a). Kepercayaan berbasiskan kalkulasi diperoleh melalui analisis ekonomi untuk menentukan apakah itu layak atau tidak bagi pihak lain untuk terlibat dalam perilaku oportunistik. Apabila dalam keterlibatan oportunistik perilaku tersebut diketahui bahwa biaya lebih besar daripada manfaat, maka kepercayaan diperlukan.

Shapiro et al (1992) menyatakan bahwa kepercayaan kalkulatif merupakan pencegahan bahwa individu tidak akan terlibat dalam perilaku oportunistik, karena takut menghadapi konsekuensi buruk, karena tidak dapat dipercaya. Menurut Gefen et al. (2003a) dalam konteks layanan e-business, konsumen akan mempercayai service provider ketika konsumen percaya bahwa service provider tidak akan memperoleh untung dengan menghancurkan kepercayaan pelanggan dan menipu mereka. Penelitian Wang et al. (2017) membuktikan terdapat hubungan positif dan signifikan antara consumer's perception of calculative-based 
trust terhadap customers' trust of services. Berdasarkan kajian teoritis tersebut, maka disusun hipotesis sebagai berikut:

Hipotesis 4: Terdapat pengaruh consumer's perception of calculative-based trust secara positif terhadap customers' trust of services.

\section{Consumer's Disposition}

Bagi konsumen, suatu transaksi dengan service provider mengandung ketidakpastian dan risiko. Dalam konteks ini, kepercayaan sangat penting untuk memfasilitasi perilaku kepercayan konsumen. Disposisi terhadap kepercayaan merujuk pada kecendetrungan umum di mana orang menunjukkan iman atau kepercayaan pada kemanusiaan yang mengadopsi sikap saling percaya terhadap orang lain (McKinght et al., 2002b). Dispoisisi terhadap kepercayaan didasarkan pada keyakinan bahwa orang lain biasanya memiliki makna yang baik dan dapat diandalkan. Disposisi seperti itu sangat penting pada tahap awal hubungan

Penelitian Wang et al. (2017) membuktikan terdapat hubungan positif dan signifikan antara disposition terhadap trust. Berdasarkan hasil penelitian terdahulu tersebut, maka disusun hipotesis sebagai berikut:

Hipotesis 5: Terdapat pengaruh consumer's disposition secara positif terhadap customers' trust of services.

\section{Customers' Trust of Services}

Kepercayaan (trust) didefinisikan sebagai "keadaan psikologis yang menyusun niat (intention) untuk menerima kerentanan (vulnerability) berdasarkan harapan niat atau perilaku orang lain (Morgant dan Hunt dalam Wang et al., 2015).

Kepercayaan konseptual dapat hadir ketika satu pihak memiliki kepercayaan diri dalam keandalan dan integritas mitra. Ketika kepercayaan dikonsep sebagai salah satu dimensi kualitas layanan (service quality), juga dapat dianggap sebagai kepercayaan pada layanan itu sendiri (Zethaml \& Berry dalam Wang et al., 2015).

Kepercyaan (trust) adalah kunci bagi hubungan yang sukses, mengurangi ketidakpastian dan risiko. Dalam dunia usaha, kepuasan konsumen (consumer satisfaction) saja tidak cukup untuk menjamin komitmen konsumen pada satu provider dalam jangka panjang.

Menurut Wang et al (2015), Grimmelikuijsen (2014), tingkat kepercayaan konsumen yang tinggi pada provider, dapat membantu memperlancar transaksi konsumen dengan provider. Kepercayaan konsumen kepada provider dapat mengeliminasi risiko yang dirasakan (perceived risks). Kepercayaan konsumen pada provider merupakan faktor kritis yang dapat mengarahkan pada adopsi yang lebih tinggi pada perilaku konsumen.

Dalam konstruk penelitian, trust digunakan untuk berbagai posisi. Misalnya, Pasuraman et al (1985, 1988) menggnakan trust (bersama-sama dengan assurance) sebagai dimensi dari konstruk kualitas layanan (service quality). Gremler dan Brown (1006) menggunakan trust sebagai antiseden loyalitas konsumen (customer loyalty).

Penelitian Wang et al. (2017) membuktikan terdapat hubungan positif dan signifikan antara trust dengan behavioral intention.Berdasarkan hasil penelitian terdahulu tersebut, maka disusun hipotesis sebagai berikut:

Hipotesis 6: Terdapat pengaruh customers' trust of services secara positif terhadap customer behavioral intention.

Konstruk ketujuh variabel tersebut tampak model penelitian ini (lihat Gambar 1), berdasarkan model dari Wang et al (2017). 


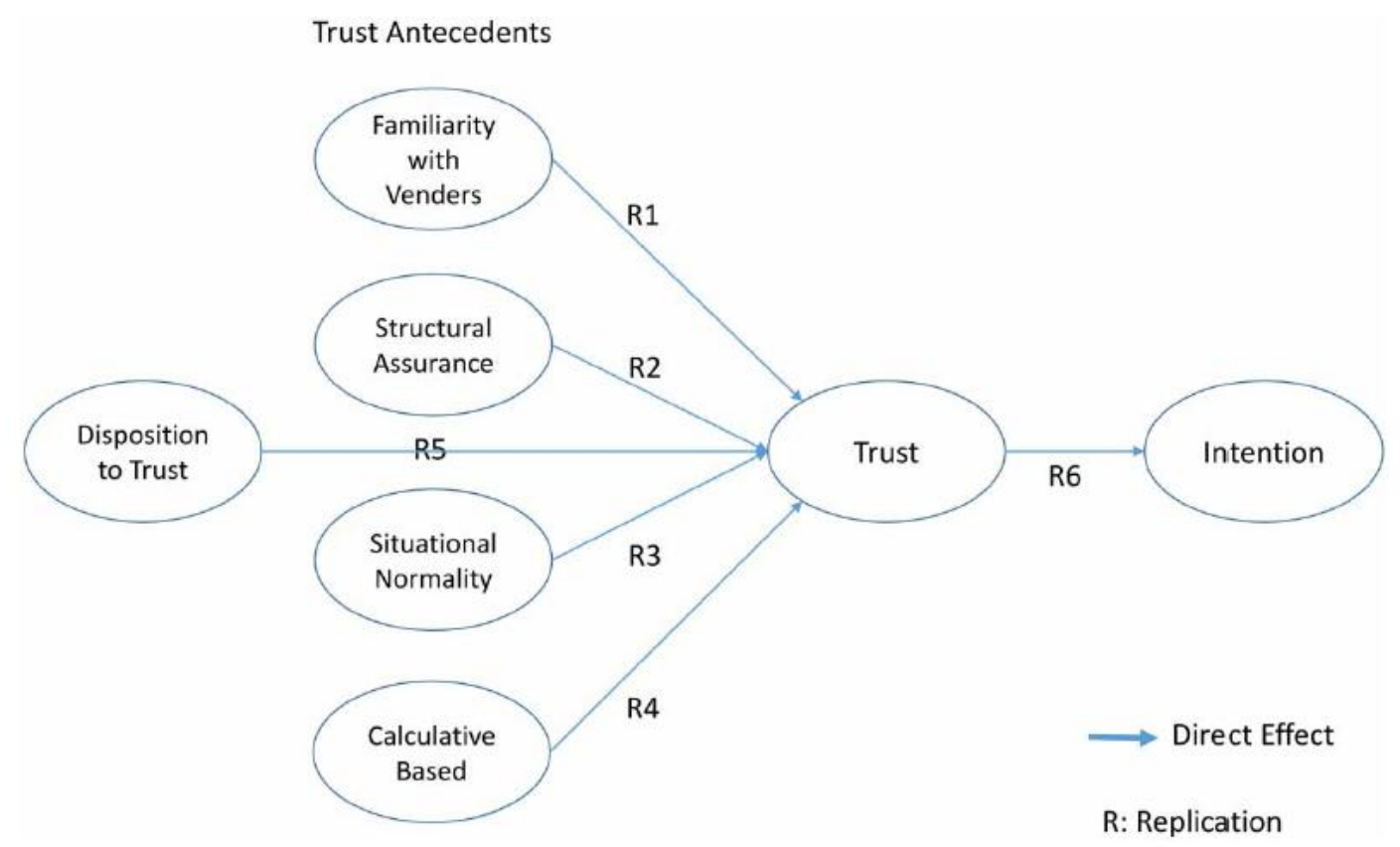

Sumber: Diadopsi dari Wang et al (2015)

Gambar 1. Model Penelitian

\section{METODOLOGI PENELITIAN}

Metode penelitian ini adalah metode kuantitatif, dalam hal ini studi kausal (causal studies), dan lebih spesifik lagi studi kausal asimetris (asymmetrical relationship). Cooper \& Schindler (2014: 136) menjelaskan, studi kausal asimetris bermakna, perubahan pada suatu variabel (variabel independen) bertanggung jawab pada perubahan variabel lain (variabel depedenden). Penelitian ini menguji pengaruh lima variabel independen (Consumer's familiartity, Consumer's perception, Consumer's dari situational normality, Consumer's disposition, dan Consumer'Trust) terhadap Trust, dan pengaruh Trust terhadap behavioral Intention.

Populasi penelitian adalah para pekerja profesional (guru, dosen, arsitek, dokter, apoteker, pengacara, notaris, akuntan, fotografer, dan lain-lain) yang berdomisili di Jakarta. Sementara itu sampel penelitian, terdiri atas penentuan jumlah sampel, dan teknik pengambilan sampel. Penentuan jumlah sampel (Tabachnick \& Fidell, 2013: 126), didasarkan pada jumlah variabel independen untuk hubungan parsial, yakni $n \geq 50+8 m$, dimana $n=$ jumlah sampel, dan $m=$ variabel independen. Berarti jumlah sampel adalah $n \geq 50+8$ m, berarti $n=50+8(6)=96$, dibulatkan menjadi 100 responden.

Jenis data utama dalam penelitian adalah data kuantitatif, dan data primer; didukung oleh data kualitatif. Teknik pengumpulan data primer melalui survei. Instrumen penelitian: kuesioner dengan skala Likert 1-4 (angka 3=ragu-ragu, dihilangkan). Data kualitatif berupa data sekunder, yakni materi teoritis dan penelitian terdahulu, melalui studi kepustakaan. Teknik analisis data menggunakan ordinary least square (OLS), dengan memakai perangkat lunak IBM SPSS versi 24.

\section{HASIL PENELITIAN}

\section{Deskripsi responden}

Responden dalam penelitian ini, sebagaimana tampak pada Tabel 1. mayoritas (78\%) laki-laki, dan minoritas (22\%) perempuan. Usia responden relatif merata untuk semua kategori, keuali kategori usia 51 tahun ke atas yang hanya tujuh persen, atau usia $\leq 25$ tahun yang hanya 11 persen. Usia 41-45 tahun adalah yang paling banyak (21\%), namun tidak berbeda jauh dengan kategori lain usia yang berada di antara 16 dan 18 persen. 
Pendidikan formal responden mayoritas (58\%) adalah sarjana strata satu (S-1). Lama responden menjalani profesi, mayoritas (45\%) adalah 3-6 tahun. Profesi responden dikategorikan ke dalam 10 profesi. Terbanyak (41\%) adalah responden dengan profesi lain-lain di luar sembilan profesi lainnya, urutan kedua adalah responden profesi konsultan (17\%), urutan ketiga adalah responden profesi dosen/pengajar (11\%). Setelah itu responden profesi akuntan, dan responden profesi pengacara yang sama-sama $8 \%$. Sementara itu responden dengan deretan persentase kecil adalah profesi notaris (4\%), arsitek (3\%), dosen (3\%), dan seniman $(2 \%)$.

\section{Deskripsi Variabel}

Hasil analisis deskriptif menunjukkan bahwa ketujuh variabel penelitian memiliki nilai rata-rata (mean) yang sedikit melebihi 3,00 $\left(\mathrm{X}_{2}, \mathrm{Y}\right.$, dan $\left.\mathrm{Z}\right)$, atau mendekati $3.00\left(\mathrm{X}_{1}, \mathrm{X}_{2}, \mathrm{X}_{3}, \mathrm{X}_{4}, \mathrm{X}_{5}\right)$. Total Nilai ratarata adalah 2,996 (Lihat Tabel 2.

Dalam menilai nilai rata-rata pada Tabel 2 tersebut digunakan rumus $\mathrm{I}=\mathrm{R} / \mathrm{K}$, di mana $\mathrm{I}=$ interval kelas, $\mathrm{K}=$ jumlah kelas (dalam hal ini 4, karena penelitian ini menggunakan skala 1-4; dan $\mathrm{R}$ adalah nilai maksimum dikurangi nilai minmum (4-1=3) (Riana, 2012: pp. 4, dan 10). Berdasarkan rumusan ini $\mathrm{I}=\mathrm{R} / \mathrm{K}=$ $3 / 4=0,75$, yang rinciannya disajikan pada Tabel 3 .

Berdasarkan Lampiran 3, maka nilai rata-rata kesemua variabel tersebut di atas maupun total nilai rata-rata ketujuh variabel sudah termasuk kategori "setuju" karena berada pada interval $2,5<\mathrm{X} \leq 3,25$.

\section{Uji Instrumen Penelitian}

Hasil uji relaibilitas secara keseluruhan untuk ke-35 item dalam kuesioner penelitian dengan menggunakan 30 responden $(\mathrm{n}=30)$, menunjukkan nilai Cronbach's Alpha 0,736 yang berarti >0,60. Hal ini menunjukkan bahwa kesemua item kuesioner adalah reliable. Demikian juga apabila uji reliabiltas dilakukan per item pada ke-35 item kuesioner, maka hasilnya > 0,70 untuk setiap item kuesioiner (lihat Lampiran 5). Hal ini menunjukkan bahwa kesemua item kuesioner tersebut realiable.

Hasil uji validitas, sebagaimana rinciannya disajikan pada Lampiran 6, menunjukkan bahwa dari 35 item kuesioner, terdapat enam item kuesioner yang tidak valid. Keenam item tersebut memiliki nilai validitas di bawah $r$ product moment 0,365 , sehingga tidak diikutsertakan pada proses penelitian selanjutnya.

\section{Uji Asumsi Klasik}

Hasil uji asumsi klasik dalam penelitian ini meliputi:

1. Hasil uji normalitas, menunjukkan data penelitian berdistribusi normal. Hal ini tampak dari gambar $p$ plot (lihat Lampiran 10) yang memperlihatkan titik-titik masih mengikuti dan mendekati garis diagonalnya (Ghozali, 2012).

2. Hasil uji multikolinearitas menunjukkan nilai tolerance $(0,776 ; 0,862 ; 0,635,0,594 ; 0,816$ untuk subkonstruk pertama; dan 1,000 untuk sub-konstruk kedua) lebih besar daripada 0,1, dan nilai variance inflation factor (VIF) $(1,288 ; 1,161 ; 1,575 ; 1,685 ; 1,225$ untuk sub-konstruk pertama; dan 1,000 untuk sub-konstruk kedua) yang lebih kecil daripada nilai 10 (Ghozali, 2012: 105; Widarjono, 2015: 65). Hal ini berarti model ini terbebas dari multikolinearitas.

3. Hasil uji heteroskedastisitas menunjukkan bahwa tidak terjadi heteroskedastisitas. Hal ini tampak dari penyebaran titik-titik pada gambar scatterplot (Lampiran 11, dan Lampiran 15) yang menyebar di atas dan di bawah angka 0 pada sumbu Y. Selain itu, tida tidak terdapat pola yang jelas pada scatterplot tersebut.

4. Hasil uji autokorelasi menunjukkan bahwa nilai Durbin Watson (DW) untuk sub-konstruk pertama $(1,839)$ dan sub-konstruk kedua $(1,831)$, keduanya lebih kecil daripada 4-dL $(2,4238)$ (Ghozali, 2012). Angka 4-dL berasal dari nilai dL dalam Tabel DW untuk $\mathrm{n}=100$ adalah 1,576; maka 4-dL= 4- 1,5762= $2.4238 \mathrm{Hal}$ ini berarti keempat model regresi tersebut terbebas dari autokorelasi.

\section{Analisis Regresi}

Analisis regresi menyangkut sub-konstruk pertama, yakni pengaruh Consumer's familiartity $\left(\mathrm{X}_{1}\right)$, Structural Assurance $\left(\mathrm{X}_{2}\right)$, Situational Normality $\left(\mathrm{X}_{3}\right)$, Calculative-Based Trust $\left(\mathrm{X}_{4}\right)$, dan Disposition to 
Trust $\left(\mathrm{X}_{5}\right)$ terhadap Trust of Services $(\mathrm{Y})$; dan sub-konstruk kedua, yakni pengaruh Trust of Services $(\mathrm{Y})$ terhadap Behavioral Intention (Z).

Berdasarkan model persamaan regresi linear berganda dan hasil perhitungan regresi, diperoleh persamaan sebagai berikut:

Trust of Services $(\mathrm{Y})=6,867$ konstanta $+0,160$ Consumer's familiartity $(\mathrm{X} 1)+0,173$ Structural Assurance (X2) -0,239 Situational Normality (X3) + 0,265 Calculative-Based Trust (X4) + 0,244 Disposition to Trust (X5).

Interpretasi dari persamaan regresi linear berganda di atas adalah sebagai berikut:

a. Nilai konstanta adalah 6.867. Hal ini berarti bahwa apabila semua variabel independen (Consumer's familiartity, Structural Assurance, Situational Normality, Calculative- Based Trust, Disposition to Trust) adalah 0 (nol), maka Trust of Services bernilai 6,867.

b. Koefisien pengetahuan Consumer's familiartity adalah $+0,160$ (bernilai postif) atau 16,0 persen. Hal ini menunjukkan bahwa Consumer's familiartity memiliki hubungan searah (arahnya sama-sama meningkat) dengan Trust of Services. Apabila Consumer's familiartity mengalami kenaikan sebesar satu satuan, maka Trust of Services (dengan asumsi koefisien variabel lainnya tetap) juga akan mengalami kenaikan 16,0 persen.

c. Koefisien pengetahuan Structural Assurance adalah $+0,173$ (bernilai postif) atau 17,3 persen. Hal ini menunjukkan bahwa Structural Assurance memiliki hubungan searah (arahnya sama-sama meningkat) dengan Trust of Services. Apabila Structural Assurance mengalami kenaikan sebesar satu satuan, maka Trust of Services (dengan asumsi koefisien variabel lainnya tetap) juga akan mengalami kenaikan 17,3 persen.

d. Koefisien pengetahuan Situational Normality adalah -0,239 (bernilai negatif) atau -23,9 persen. Hal ini menunjukkan bahwa Situational Normality memiliki hubungan sebaliknya (tidak searah) dengan Trust of Services. Apabila Situational Normality mengalami kenaikan sebesar satu satuan, maka Trust of Services (dengan asumsi koefisien variabel lainnya tetap) juga akan mengalami penurunan -23,9 persen.

e. Koefisien pengetahuan adalah $+0,265$ (bernilai positif) atau $+26,5$ persen. Hal ini menunjukkan bahwa Calculative- Based Trust memiliki hubungan searah (arahnya sama-sama meningkat) dengan Trust of Services. Apabila Calculative- Based Trust mengalami kenaikan sebesar satu satuan, maka Trust of Services (dengan asumsi koefisien variabel lainnya tetap) juga akan mengalami penurunan $+26,5$ persen.

f. Koefisien pengetahuan Calculative- Based Trust adalah $+0,265$ (bernilai positif) atau $+26,5$ persen. Hal ini menunjukkan bahwa Calculative- Based Trust memiliki hubungan searah (arahnya sama-sama meningkat) dengan Trust of Services. Apabila Calculative- Based Trust mengalami kenaikan sebesar satu satuan, maka Trust of Services (dengan asumsi koefisien variabel lainnya tetap) juga akan mengalami penurunan $+26,5$ persen.

g. Koefisien pengetahuan Disposition to Trust adalah $+0,244$ (bernilai positif) atau $+24,4$ persen. Hal ini menunjukkan bahwa Disposition to Trust memiliki hubungan searah (arahnya sama-sama meningkat) dengan Trust of Services. Apabila Disposition to Trust mengalami kenaikan sebesar satu satuan, maka Trust of Services (dengan asumsi koefisien variabel lainnya tetap) juga akan mengalami penurunan + 0,244 persen.

\section{Koefisien Determinasi $\left(\mathbf{R}^{2}\right)$}

Hasil penelitian mengenai koefisien determinasi $\left(\mathrm{R}^{2}\right)$ terdiri atas dua sub-konstruk.

1. Sub-kontruk pertama, yakni pengaruh Consumer's familiartity $\left(\mathrm{X}_{1}\right)$, Structural Assurance $\left(\mathrm{X}_{2}\right)$, Situational Normality $\left(\mathrm{X}_{3}\right)$, Calculative-Based Trust $\left(\mathrm{X}_{4}\right)$, dan Disposition to Trust $\left(\mathrm{X}_{5}\right)$ terhadap Trust of Services $(\mathrm{Y})$ menghasilkan $R$ square $\left(\mathrm{R}^{2}\right)$ 0,308 dan adjusted $R$ square 0,271. Penelitian ini memilih adjusted $R$ square, berarti 0,271 atau 27,1 persen. Trust of Services (Y) dapat dijelaskan oleh kelima variabel independen tersebut sebesar 27,1 persen yang berarti sisanya $(100 \%-27,17 \%=72,3 \%)$ dijelaskan oleh variabel independen lain di luar kelima variabel independen tersebut

2. Sub-konstruk kedua, yakni pengaruh Trust of Services (Y) terhadap Behavioral Intention (Z) menghasilkan $R$ square $\left(\mathrm{R}^{2}\right)$ 0,083 dan adjusted $R$ square 0,073 . Penelitian ini memilih adjusted $R$ square, berarti 0,073 atau 7,3 persen. Behavioral Intention (Z) dapat dijelaskan oleh Trust of Services $(\mathrm{Y})$ sebesar 7,3 persen yang berarti sisanya $(100 \%-7,3 \%=92,7 \%)$ dijelaskan oleh variabel independen lain di luar variabel independen Trust of Services (Y). 


\section{Uji Hipotesis}

Sesuai dengan hipotesis penelitian, keseluruhan uji hipotesis adalah nilai koefisien regresi dan uji t, karena hanya menyangkut pengaruh parsial antar-variabel.

1. Pengaruh Consumer's familiartity $\left(\mathrm{X}_{1}\right)$ terhadap Trust of Services $(\mathrm{Y})$. Nilai koefisien regresinya 0,160 yang berarti berpengaruh positif. Nilai t hitung signifikansi t hitung adalah 0,089 yang berarti lebih besar daripada nilai signifikansi yang ditetapkan $(0,05)$, yang berarti pengaruhnya tidak signifikan. Berarti, Consumer's familiartity $\left(\mathrm{X}_{1}\right)$ berpengaruh positif terhadap Trust of Services $(\mathrm{Y})$, namun tidak signfikan.

2. Pengaruh Structural Assurance $\left(\mathrm{X}_{2}\right)$, terhadap Trust of Services (Y). Nilai koefisien regresinya 0,173 yang berarti berpengaruh positif. Nilai t hitung signifikansi t hitung adalah 0,020 yang berarti lebih kecil daripada nilai signifikansi yang ditetapkan $(0,05)$, yang berarti pengaruh Consumer's familiartity $\left(\mathrm{X}_{1}\right)$ terhadap Trust of Services (Y) signifikan. Berarti, Structural Assurance $\left(\mathrm{X}_{2}\right)$, berpengaruh positif dan signifikan terhadap Trust of Services (Y).

3. Pengaruh Situational Normality (X3) terhadap Trust of Services (Y). Nilai koefisien regresinya -0,239 yang berarti berpengaruh negatif. Nilai thitung signifikansi t hitung adalah 0,054 yang berarti lebih besar daripada nilai signifikansi yang ditetapkan $(0,05)$, yang berarti pengaruhnya tidak signifikan. Berarti, Situational Normality (X3) berpengaruh negatif terhadap Trust of Services (Y), namun tidak signfikan.

4. Pengaruh Calculative- Based Trust $\left(\mathrm{X}_{4}\right)$ terhadap Trust of Services (Y). Calculative- Based Trust $\left(\mathrm{X}_{4}\right)$. Nilai koefisien regresinya 0,265 yang berarti berpengaruh positif. Nilai $\mathrm{t}$ hitung signifikansi $\mathrm{t}$ hitung adalah 0,006 yang berarti lebih kecil daripada nilai signifikansi yang ditetapkan $(0,05)$, yang berarti pengaruh Calculative- Based Trust $\left(\mathrm{X}_{4}\right)$ terhadap Trust of Services (Y) signifikan. Berarti, CalculativeBased Trust $\left(\mathrm{X}_{4}\right)$ berpengaruh positif dan signifikan terhadap Trust of Services $(\mathrm{Y})$.

5. Pengaruh Disposition to Trust $\left(\mathrm{X}_{5}\right)$ terhadap Trust of Services $(\mathrm{Y})$. Nilai koefisien regresinya 0,244 yang berarti berpengaruh positif. Nilai t hitung signifikansi t hitung adalah 0,015 yang berarti lebih kecil daripada nilai signifikansi yang ditetapkan $(0,05)$, yang berarti pengaruh Disposition to Trust $\left(\mathrm{X}_{5}\right)$ terhadap Trust of Services (Y) signifikan. Berarti, Disposition to Trust $\left(\mathrm{X}_{5}\right)$ berpengaruh positif dan signifikan terhadap Trust of Services (Y).

6. Pengaruh Trust of Services (Y) terhadap Behavioral Intention (Z), Nilai koefisien regresinya 0,244 yang berarti berpengaruh positif. Nilai $t$ hitung signifikansi $t$ hitung adalah 0,015 yang berarti lebih kecil daripada nilai signifikansi yang ditetapkan $(0,05)$, yang berarti pengaruh Trust of Services (Y) terhadap Behavioral Intention (Z), ) signifikan. Berarti, Trust of Services (Y) berpengaruh positif dan signifikan terhadap Behavioral Intention (Z),

\section{Diskusi}

Hasil penelitian ini hampir seluruhnya mendukung hasil penelitian Wang et al. (2017), kecuali untuk variabel situational normality yang berpengaruh negatif terhadap trust of services. Hasil penelitian ini membuktikan bahwa jika hendak meningkatkan keinginan publik agar memberikan wakaf tunainya, maka kuncinya adalah pada kepercayaan, yakni kepercayaan wakif terhadap nazhir. Berarti hasil penelitian ini juga mendukung hasil penelitian Suganda (2014), Sanusi (2015), Osman (2015), Tho'in (2915), Ricket (2016), Yunanda, Shafii, dan Taerq (2016), Hasan \& Siraj (2017), Saiti (2017), Yaacob \& Nahar (2017)(, Fauzi et al (2019), Hasan et al. (2019), dan Jamila \& Alhabshi (2019)/ Kesemua penelitian itu secara umum mendukung kesimpulan bahwa transpransi, kejujuran, akuntabilitas, adalah kunci kepercayaan waqif kepada nadzir di berbagai negara.

Meningkatkan kepercayaan publik terhadap wakaf tunai, antara lain dengan meningkatkan performa pada variabel-variabel yang menjadi anteseden dari kepercayaan publik ini. Berikut adalah hal-hal yang dapat dilakukan oleh nadzir sebagai perseorangan maupun institusi:

1. Familiarity. Berarti nadzir harus seecara terprogram mengenalkan diri pada prosepek wakif. Wakif harus mengenal dengan baik siapa calon nazhir-nya, bagaimana cara kerjanya, bagaimana bentuk pertanggungjawabannya, dan seterusnya. Pengenalan nazhir ini bisa memungkinkan wakif lebih percaya jika wakaf tunai diserahkan kepada nazhir tersebut. Usaha nazhir yang baru tentu harus lebih meyakinkan apabila wakif memiliki pengalaman buruk dengan nazhir0nazhir sebelumnya.

2. Structural assurance. Wakif harus memperoleh jaminan struktural, seperti regulasi, atau jaminan dari pihak yang lebih berwenang seperti BAZIS mengenai sejauh mana wakaf tunai mereka bisa terjamin 
keamanan dan penyalurannya. Wakif harus merasa yakin bahwa pihak yang berwenang dapat menjamin wakaf tunai mereka, sekalipun misalnya terjadi penyelahgunaan oleh nazhir atau pihak lain.

3. Situational normality. Proses trasaksi wakaf tunai harus dapat dilihat normal oleh wakif. Wakif harus merasa yakni bahwa wakaf tunai ini bukan sesuatu hal yang tidak normal jika dilihat dari prosedur/mekanisme, dan peraturan yang ada terkait dengan wakaf.

4. Calculative based trust. Wakif memiliki kaulkulasi tertentu jika hendak memberikan atau tidak memberikan wakaf tunai. Pihak nazhir harus mampu memberikan kalkulasi dari beberapa aspek yang dapat meyakinkan wakif agar lebih percaya pada wakaf tunai.

5. Disposition to trust. Pihak nazhir harus meyakinkan pihak wakif bahwa para pemangku kepentingan dalam wakaf tunai adalah orang-ornag yang amanah, orang yang berintegritas tinggi.

\section{KESIMPULAN}

Berdasarkan hasil penelitian tersebut dapat disimpulkan bahwa hasil penelitian ini mendukung konstruk yang dikembangkan Wang et al (2015).

Hasil penelitian tersebut menyarankan bahwa:

1. Secara teoritis, kelima variabel indepdenden (Consumer's familiartity, Structural Assurance, Situational Normality, Calculative- Based Trust, dan Disposition to Trust), terbukti mempengaruhi Trust of Service. Begitu pula Trust of Services (Y) mempengaruhi Behavioral Intention (Z). Oleh karena itu konstruk ini dapat digunakan untuk diuji lebih lanjut dalam penelitian selanjutnya.

2. Secara praktis, institusi penyelenggara wakaf tunai, maupun pemangku kepentingan lainnya dapat memperhatikan hasil penelitian, terutama mengenai pentingnya kepercayaan, dan mengenai variabelvariabel independen yang mempengaruhi kepercayaan. Para pemangku kepentingan harus memperhatikan bahwa faktor kepercayaan publik kepada institusi wakaf tunai sangat tergantung pada kepercayaan publik (dalam hal ini wakif) terhadap institusi wakaf tunai.

\section{DAFTAR PUSTAKA}

Ahmed, U.; Mohammed, M.O.; Faosiy, O.A.; Daud, N.M. (2016), Investigating the influence of public trust on the revival of waqf institution in Uganda. Middle-East Journal of Scientific Research, 23 (6), 1165 1172 .

Atabik, A. (2014). Manajemen pengelolaan wakaf tunai di Indonesia. Working paper, dapat diunduh pada http://journal.stainkudus.ac.id/index.php/Ziswaf/article/view/1527.

Atan, N.A.; Johari, F. (2017). A review on literature on literature of waqf for poverty alleviation between 2006-2016. Library Philosophy and Practice (e-journal), 1486.

Cooper, D.R.; \& Schindler, P.M. (2014). Business Research Methods. Twelfth edition. New York: McGrawHill

Fahham. A.M. (2015). Pengelolaan wakaf tunai di lembaga pengelola wakaf dan pertanahan pengurus wilayah Nahdlatul Utama Daerah Istimewa Yogyakarta. Aspirasi, 6(1), 27- 36.

Fauzi, M.H.B.; Yahya, S.; Hanaysha, J.R.; Haron, M.S.; \& Zahrin, S.N.A. (2019). The impact of trust in cash waqf contribution: a case study of study of wakaf Selangor Mualamat (WSM) service of Bank Mualamat Malaysia Berhad (BMMB). International Journal of Business, Economics and Law, 18(2), $1-11$.

Gefen, D. (2002), Nurturing client's trust to encourage engagement success during the custyomization of ERP systems. Omega, 30(4), 287-299.

.(2003). TAM or just plain habit: A look at experienced online shoppers. Journal of End User Computing, 15(3), 1-13.

, Karahanna, E.; \& Straub, D.W. (2003a). Potential and repeat e-Consumers: The role of and trust visXa-vis TAM. IEEE Transactions on Engineering Management, 50(3), 307- 321.

Ghozali, I. (2012). Aplikasi Analisis Multivariate dengan Program IBM SPSS 20. Semarang: Badan Penerbit Universitas Diponegoro. 
Gremler, D.D.; \& Brown, S.W. (1996). Service loyalty: Its nature, importance, and implications. In B. Edvardsson, S.W.Brown, R. Johnstpn, E.E. scheuing (ed). Advancing service quality: A global perspective (pp. 171-180). New York, NY: International Service Quality Association.

Grimmelikhuijsen, S.G.(2014). The effects of transparency on the perceived trustwoerthniness of a government organization: eviedence from on online experiment. Journal of public administration Theory and Research 24(1), 137-157.

Haron, M.; Komarudin, M.K; Fauzi, N.A.M.; Ariff, M.M.; \& Zainuddin, M.Z. (2016). Cash waqf collection: Any potential factors to influence it? International Journal of Business, Economics and Law, 9(2), 2733.

Hasan, R.; Siraj, S.A.; Mohammad, M.H.S. (2019). Antecedents and Outcome of Waqif's in Waqf Institution. Journal of Economic Cooperation and Development, 38(4), 155-180.

Hasan, R.; Siraj, S.A. (2017). Toward developing a model of stakeholder trust in waqf institutions. Islamic Economic Studies, 25, 85-100.

Jamila, K.R.; Alhabshi, S.M. (2019). Waqf financial reporting and transparency: case of ar-Raudhatul Hasanah Islamic Boarding School. Working paper, dapat diunduh pada http://jurnal.uinsu.ac.id/index.php/JAKS/article/view/4172.

McKnight, D.H.; \& Choudhury, V.; Kacmar. (2002a).. Developing and validating trust measures for ecommerce: An intehrity typology. Information Systems Research, 13(3), 334-359/

.(2003b). The impact of initial consumer trust on intentions to transact with a Web site: A trust building model. Jourmal of Strategic Information Systems, 11(3-4), 297-323.

Osman, A.F.; Mohammed, M.O.; Fadzil, A. (2015). Factor influencing cash waqf giving behavior: a revised theory of planned behavior, 33- 48. Dapat diunduh pada http://gbse.com.my/JurnalMs3348Amirul.pdf.

Parasuraman, A.; Zeithaml, V.A.; \& Berry, L.L. (1985). A conceptual model of service quality and its implications for future research. Journal of Marketing, 49(3); 41-50.

.(1988). SERVQUAL: A multiple-item scale for measuring consumer percepstions of service quality. Journal of Retailing, 64(1): 12-40.

Riana, D. (2012). Statistika Deskriptif itu Mudah. Tangerang Selatan: Jelajah Nusa

Ricket, J.M.; (2016). The relationship between transparency, consumer trust and willingness to share data: A vignette survey. 7th IBA Bachelor Thesis Conference, July 1st, 2016, Enschede, The Netherlands.Dapat diunduh pada https://pdfs.semanticscholar.org/497c/3e5716e92e58a98509d01e4e6d1b6afa57a3.pdf.

Saiti, B. (2017). The role of the waqf and trust commission (WTC) in Zanzibar: problems and prospects.Working Paper pada https://www.researchgate.net/publication/314964823_The_Role_of_the_Waqf_and_Trust_Commissio n_WTC_in_Zanzibar_Problems_and_Prospects.

Sanusi, S. (2015). Tha Management of Cash Waqf: Toward Socio-Economic Development of Muslims in Malaysia. Jurnal Pewngurusan, 43, 3-12.

Shapiro, D.L.; Sheppard, B.H.; \& Cheraskin, L. (1992). Business on handshake. Negotiation Journal, 8(4), 365-377.

Suganda, A.D. (2014). Konsep Wakaf Tunai. Islamiconomic, Jurnal Ekonomi Islam, 5 (2), 1-15.

Syauqi, M.A. (2014). Optimalisasi pengelolaan wakaf uang untuk kesejahteraan umum. Kanun Jurnal Ilmu Hukum, 63(16), 369-383.

Tabachnick, B.G.; \& Fidell, S.L. (2013). Using Multivariate Statistics. Sixth Edition. Boston: Pearson Education, Inc.

Tho'in, M.; \& Prastiwi, I.E.(2015). Wkaf Tunai Perspektif Syariah. Jurnal Ilmiah Ekonomi Islam, 01(01), 61- 74. 
Wang, S.W.; Ngamsiriuom, W.; \& Hsieh, C.H. (2015). Trust disposition, trust antecedents, trust, and behavioral intention. The Service Industries Journal, 35(10), 555-572.

Widarjono, A. (2015). Analisis Multivariat Terapan dengan Program SPSS, AMOS, dan SMARTPLS. Edisi kedua. Yogyakarta: UPP STIM YKPN.

Yaacob, H.; \& Nahar, H.S. (2017). Investigating awqaf management, accounting, and investment practices in Malaysia: the cas of state religious institution. GJT, 7(1), 60-70.

Yunanda, R.A.; Shafii, Z.; tareq, M.A. (2016). Accountability of Islamic Based Non-Profit Sector: The Case of Waqf Organizations. Jurnal Ekonomi dan Bisnis Islam, 2(2), 105- 124. 